\title{
Ethical Investment and Portfolio Theory: Using Factor Analysis to Select a Portfolio
}

\author{
John Simister, Richard Whittle \\ Accounting, Finance and Economics Department, Manchester Metropolitan University, Manchester, UK \\ Email: J.G.Simister@mmu.ac.uk
}

Received December 26, 2012; revised January 27, 2013; accepted February 11, 2013

\begin{abstract}
Ethical investments are a now a considerable sector in the investment market, with the Financial Times running the headline "Green and ethical investment comes of age" (Shepherd, [1]). Claudia Quiroz (lead fund manager for Cheviot Climate Assets Fund) predicts a strong future for ethical investment, with sustainable investment becoming a growing theme (Hoskin [2]). Much previous research in the "ethical investment" field divides investments into two categories: acceptable or unacceptable. This paper builds on the work of Barracchini and Addessi [3], in viewing how "ethical" an investment is to be a different dimension - each investment is seen as being on a continuum, from "least ethical" to "most ethical". This paper takes the work of Barracchini and Addessi [3] from a theoretical construct to an approach which can be applied by practitioners. In order to make a workable method, this paper uses conventional portfolio analysis (which focus on risk and return), combined with principal components analysis in order to minimize the risk of a portfolio. It adopts a specific functional form for the saver's utility function, to assess which assets appears most desirable using that person's values.
\end{abstract}

Keywords: Ethical Investment; Portfolio; Principal Components Analysis

\section{Introduction}

Wimmer [4] reported on Social Responsibility (SR) in investment: "While some research on how SR mutual funds can include ESG-scores in the optimization in the second stage has recently been published (e.g. Barracchini and Adessi, 2012; Dorfleitner and Utz, 2012), it still remains to be implemented in practice". This paper seeks to bridge the gap between the mathematical analysis of Barracchini and Addessi [3], and the need for a decision-making method which can be used by professsional fund managers or by individual savers.

Ethical investment is of growing importance: for example, a 1997 survey found 39\% of respondents wanted their pension scheme to be based on ethical behavior, even it led to a reduction of their pension (Havemann and Webster, [5]). Recent research on "impact investing" (where both financial yield and ethical return is considered) has identified this market as having huge growth potential (Arosio, [6]). A YouGov survey in 2011 found $43 \%$ of UK 18 - 23 years old (the investors of the future) have an interest in investments with both a financial and ethical return (Shepherd, [1]).

The main focus of this paper is on shares and bonds issued by private companies. This paper assumes there are differences between the behaviors of different firms, such that some firms attract approval whereas other firms are assumed to behave in undesirable ways. This paper does not attempt to offer a method to assess which investments are "ethical"- this may be an impossible task, because each person has different values. Different investors may have different views on this (Havemann and Webster, [5])—for example, some people may seek to invest in nuclear power generation, as a way to reduce the threat of global warming; other investors might consider nuclear power too risky, because of experiences such as Chernobyl. This paper assumes that for any one investor, some (potential) investments are more ethical than others; and that there is some agreement between investors about which investments are relatively ethical (if there were no such agreement of common values, we would not expect to see any clear link between ethical behavior in a firm, and return on the firm's shares).

In 2010, failure of the BP "Deepwater Horizon" gas platform led to a huge oil spill in the Gulf of Mexico. Similar problems have occurred to BP in other cases, leading many people to conclude this corporation behaves inappropriately-perhaps BP take excessive risks in order to maximize their profit. Other firms boycotted for unethical behavior include Shell (Havemann and Webster, [5]) and Nestlé (BMAC), [7]). Perhaps ethical investments have lower risk than firms whose only aim is profit-maximizing? These examples suggest there is a 
risk for a firm in pursuing the highest possible return on investment, perhaps associated with cutting corners on safety: it could lead to consumer boycotts.

Havemann and Webster [5] suggest a different perspective: they suggest that if news reveals a firm's behavior is unethical, this will reduce the firm's share price-in some studies, the share price can fall by up to $3 \%$. The effect of a price fall will tend to increase the expected return (ceteris paribus); if this pattern applies generally, then unethical investments tend to have a higher return-which is equivalent to saying ethical investments tend to have a lower return. However, Shepherd [1] reports that international agencies predict an increase in global food consumption of around $50 \%$, an increase in energy consumption of around $50 \%$ and an increase in the need for fresh water of around 30\% from 2011 levels; this, and the possible need to adjust to climate change, prompted The Mercer Carbon Trust [8] to consider an overall long term increase in general investment risk. Green and ethical funds have the ability to mitigate this risk with long term sustainable investment, and as such may become the long term winners of the investment game.

\section{Literature Review on Ethical Investment}

It could be argued that a rational investor would seek to maximize his or her return, subject to a particular risk level. In conventional economic analysis, "One of the greatest of economic myths is the animal known as rational economic man. This mythological beast is frequently described in introductory economics books $\cdots \mathrm{He}$ is highly individualistic - he is never seen in a pack or an unruly mob-and only acts to optimise his own utility. He makes his decisions based on cold rationality, rather than coarse emotion. He knows what he likes, and his preferences never change. He knows everything there is to know about prices, and he is blessed with an Apollon ability to look into the future. He never slips up" (Orrell [9]). These economic textbook writers refer to men and women, rather than implying men behave differently to women. Some empirical evidence casts doubt on this assumption, such as attitudes to buying "Fair Trade" in Special Eurobarometer 375 (European Commission, [10]). $47 \%$ of European respondents said they would not pay more for Fair Trade products; 33\% said they would pay up to $5 \%$ more; $15 \%$ of respondents would pay $6 \%-10 \%$ more; and $4 \%$ of respondents would pay over $10 \%$ more for Fair Trade products (there was missing data for $6 \%$ of respondents). Note that this not a simple binary choice (where some people are ethical but others are not): some consumers are only prepared to pay slightly more, whereas others are prepared to pay over $10 \%$ extra.

Empirical evidence suggests humans are not always motivated by self-interest. The existence of "ethical in- vestment” organizations implies at least some investors consider that risk and return are not the only considerations when choosing an investment portfolio. In a 2011 YouGov survey, around 25\% of British investors wanted information (fund brochures, future investment plans and so on) on the ethical status of their investments-according to Shepherd [1], especially if their fund managers or even pension funds (traditionally an area of reasonably passive investment) fund firms with poor climate change records or culpability. Investors may ensure their funds are not contributing to excessive executive rewards.

"The green and ethical sector finds itself at the heart of the UK recovery. The (aforementioned) YouGov research found that $53 \%$ of retail investors believe that taking social and environmental issues into account in financial decisions has an important part to play in the UK's economic recovery. Green and ethical investment has entered mainstream finance" (Shepherd, [1]; underlining added for emphasis).

Havemann and Webster [5] refer to an "investible universe" of investments which satisfy ethical criteria; for example, investors may avoid firms dealing with alcohol or tobacco, pornographic, or military products; which use animal testing; or which are thought to harm the environment (Havemann and Webster, [5]). People disagree about which forms of behavior are unethical. For this paper, we assume there is a common core of values held by most investors, in which some activities are generally seen as more acceptable than others-for example, solar power is generally seen as "better" than coal-fired electricity generation, due to the effects of burning fossil fuels on global warming: in a 2011 Eurobarometer survey, $94 \%$ of respondents were in favor of the use of "solar energy" in their country, and $48 \%$ were opposed to using coal as an energy source (European Commission, [11]).

The current YouGov definition suggests that ethical finance is a positive investment in activities that benefit society and the environment, rather than the traditional exclusion of companies involved in undesirable practices (Shepherd, [1]). In essence, investors have switched from avoiding a negative to creating a positive.

Conventional economics assumes that the only aim of a firm should be to maximize profit, subject to constraints such as obeying laws. In the view of Milton Friedman [12], a corporate executive should run the business in accordance with the desires of the firms' owners (shareholders and bondholders), "which generally will be to make as much money as possible while conforming to the basic rules of the society, both those embodied in law and those embodied in ethical custom". In recent decades, this was widely accepted by large corporations: "The singularity of this goal was so prevalent that board members 
of very large corporations-themselves decent individuals committed to a range of values-believed that it was unethical to consider issues other than shareholder value in their deliberations" (Sampford and Berry, [13]). According to Richardson [14], the "separation theorem" suggests the best way for an investor to help is to maximize their own income without limiting their portfolio to ethical investments, and use the income from their portfolio to give more to charity. Writers analyzing "Corporate Social Responsibility" approach see things as more complicated: for example, Carroll [15] claimed each firm must consider four aims: philanthropy, ethics, legal responsibilities, and profit-maximization; this suggests that a firm's managers may choose which to prioritize-some firms placing more emphasis than others on profit maximization.

If ethical firms are prevented from operating in numerous industries, we might expect ethical investments in general to have a lower return than firms with no ethical restrictions. Havemann and Webster [5] wrote "any investment strategy other than holding a portfolio looking exactly like the market in general involves a less than optimal balance of risk and return". Richardson [14] reports that some writers consider ethical investment to have a lower return (than the market as a whole) for a given risk; whereas others consider ethical investment to have higher risk (than the whole market), because they are less diversified - due to excluding some stocks. However, some evidence suggests different conclusions: according to Richardson [14], "Various studies suggest that because inefficient speculative booms disturb capital markets, it may be possible for ethical investment strategies to maximise income". Ballestero et al. [16] found that a portfolio of "strong green" ethical investments tend to have lower returns than a portfolio obtained from applying conventional (expected value-variance) portfolio theory, but this result is not statistically significant in the case of "weak green" ethical investments. Havemann and Webster [5] conclude "This research indicates that investment universes constructed on an ethical basis can provide a balance of risk and return which doesn't look materially different from the FTSE All-Share Index".

Some writers claim ethical investment can have a higher return than conventional assets. Havemann and Webster [5] compared the performance of firms based on five indices of ethical behavior such as "Environmental damage avoidance", and found firms in four of these five indices outperformed the return in FTSE All-share index from December 1990 to May 1999. For two of these five indices, the volatility of ethical firms was lower than that of the FTSE all-share index. Firms in one of the five indices (the "Charities avoidance' index") had higher growth and lower risk than the FTSE index: Havemann and Webster [5] report a Beta value of 0.89 for the Cha- rities' avoidance index. This appears to make most FTSE investors sub-optimal, in that they could have produced better returns and lower risk simply by avoiding firms carrying out activities which (according to many charities) harm society. Note, however, that the increased return is only $0.08 \%$ higher than the FTSE all-share index, and this was only over a relatively short period-about ten years. Havemann and Webster [5] warn that it is difficult to assess if there is a trade-off between ethical behavior and maximizing return.

Arosio [6] suggests that it is difficult to compare the expected returns on "impact investing" (one form of ethical investment) with other investments having a similar risk; but "We benchmarked these anticipated returns against high-performing debt and equity indices, such as the US' S\&P 500, Russell 2000 Growth, and the PIMCO Total return and J. P. Morgan Emerging Market Bond Index, and found the expected performance of these impact investments to be comparable if not better”. One ethical fund, the Amity International Fund (Ecclesiastical), is consistently in the top 25\% of IMA Global Growth Sector Funds, and in the decade up to August 2011 outperformed the global growth sector by more than $69 \%$; this helps to dispel the prevailing market belief that it is necessary to sacrifice profit to achieve ethical principles (Shepherd, [1]).

It is possible that ethical investment has higher transaction costs (than the whole market) (Richardson, [14]). However, Havemann and Webster [5] suggest there may be lower costs for fund managers focusing only on ethical investments, because those managers have a smaller range of stocks to keep track of.

When deciding on which assets to include in a longterm portfolio (such as a pension fund), it seems appropriate for fund managers to use forecasting to assess how the ethical rating of each stock will change in future years. For example, if global warming continues as most climate scientists predict, this is likely to form an increasing priority for savers. One possible approach is to seek an ethical score for each asset for each year, and use regression analysis (such as ARIMA, to control for autocorrelation) to predict future ethical scores-assuming the present trends continue.

It is relatively straightforward to choose a portfolio from a range which meets the investor's tastes, imposing a binary choice in which each investment is classified as "ethical" or "not ethical" (and using conventional portfolio theory). But is this binary choice sufficiently detailed? Ethical investment could be positive (choosing to invest in firms with behavior the investor likes), or negative (not investing in firms which behave in ways the investor dislikes) (Havemann and Webster, [5]), suggesting assets should be divided into three types rather than two. Many 
writers in the field of ethical investment go further, and see ethical behavior as being on a continuum (Havemann and Webster, [5]; Barracchini, [17]).

\section{Mathematical Model}

Barracchini and Addessi [3] offer a new approach to incorporating ethics into conventional analysis of risk and return in portfolio theory. In their approach, the extent to which an investment is "ethical” forms a third dimension, in addition to the two traditional dimensions of risk and return. However, analysis in Barracchini and Addessi [3] has limited scope: it indicates that an investor prefers a more ethical investment if different investments have the same risk and return, and prefers an investment with a higher expected return among investments which are equally ethical. They state on page 40 that "a quadratic form with three variables can be derived" if the utility function is differentiable; this seems unlikely to be enough detail for an investor (or even a commercial investment agency) to apply. Hence, we provide a more detailed utility function.

To begin, imagine an investor with no interest in ethical issues had this utility function:

$$
U=k r^{\beta} / \sigma^{\varphi}
$$

where $k$ is a constant, $r$ is the expected return on the investment, and $\sigma$ is a measure of risk. A higher utility can be obtained for the investor by finding a higher rate of return (if risk is unchanged), or a lower risk (for a given return). This gives a typical (risk-averse) investor an indifference curve like $I_{1}$ in Figure 1. The diagrams in Barracchini and Addessi [3] are different to those in this paper, but convey similar ideas.

Now, extend this model to ethical investments: if the ethical "score" E for each investment is known, we could consider an investor's choice to increase to $I_{2}$ if investments with the same risk and return profiles can be obtained. Hence, the utility function becomes

$$
U=k E^{\alpha} r^{\beta} / \sigma^{\varphi}
$$

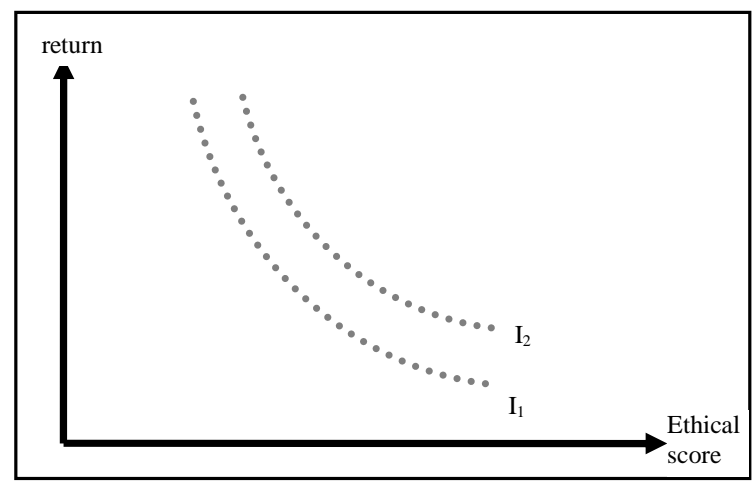

Figure 1. Indifference curves dependent on ethical score and return. where $\alpha, \beta$ and $\varphi$ are constants between zero and 1 . Now, revert temporarily to conventional portfolio theory, to investigate how this is related to portfolio risk.

Figure 2 shows selected combinations of four stocks: A, B, C and D. Of these four, stocks A and B are conventional (profit-maximising) stocks, whereas $C$ and $D$ are ethical investments. We assume there is a negative correlation between the risk of stock $\mathrm{C}$ and stock $\mathrm{D}$, giving the conventional C-shaped curved line. The curved line $A B$ shows various combinations of two conventional stocks. A saver who restricted their portfolio to "ethical" stocks could choose to accept a lower return, and hence their choice would be on the curved line CD.

This is a relatively simple case, of a binary choice: ethical versus conventional stocks. However, Barracchini and Addessi [3] take this model to a higher level of complexity, by allowing for the possibility that the "ethical" score of an asset can vary continuously on a scale. They add a third dimension to a diagram such as Figure 3; this (more complicated) task is represented in Figure 4. The key difference between these figures is that Figure $\mathbf{4}$ has a third dimension, represented as a diagonal line at the bottom-left corner of Figure 4 (this dimension can be imagined as coming towards the reader).

In conventional portfolio theory, it is assumed that savers can put some of their money in a risk-free finan-

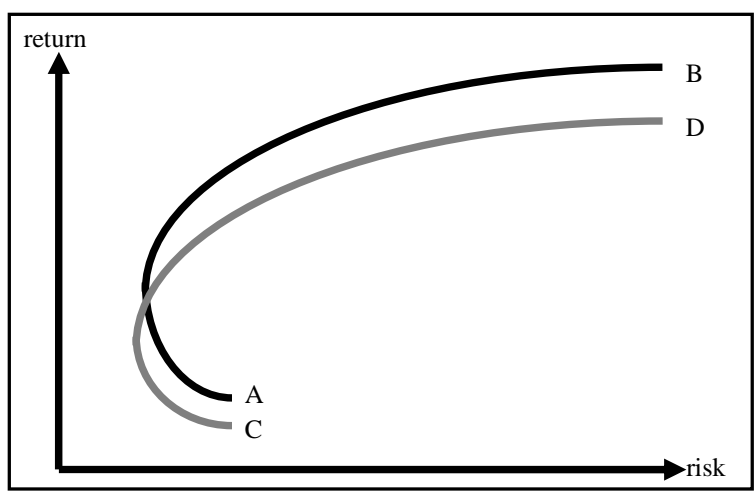

Figure 2. Portfolio theory with ethical investments.

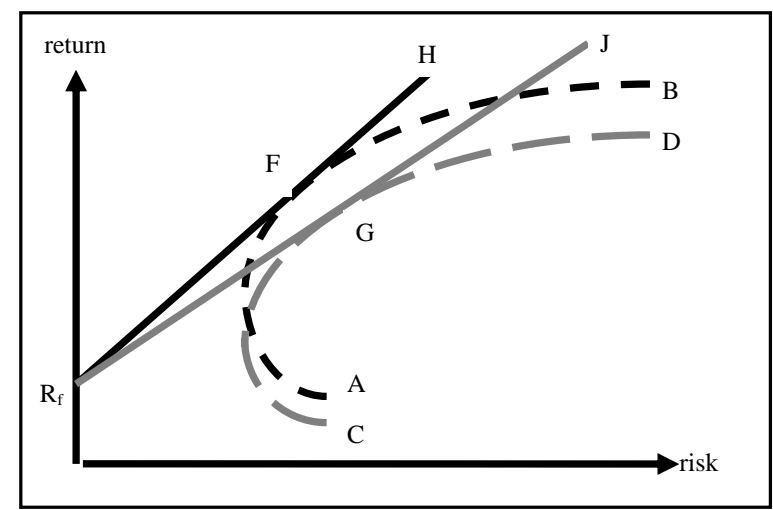

Figure 3. Stocks with a risk-free portfolio. 


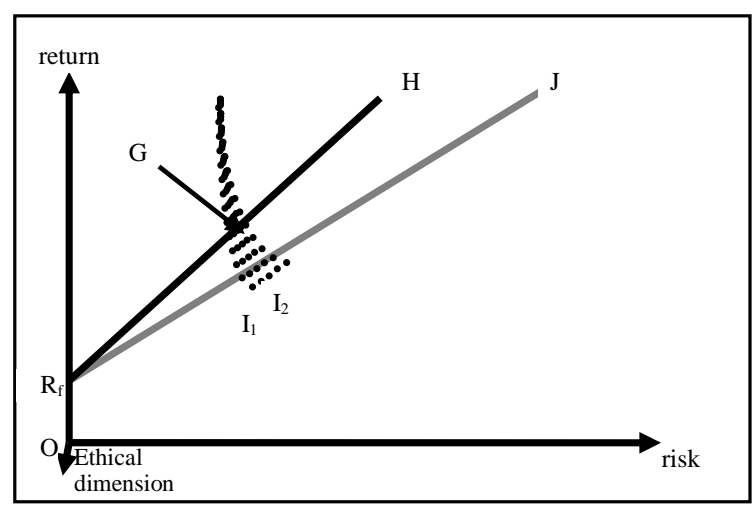

Figure 4. Choice for an investor.

cial asset. By adding a risk-free stock $\mathrm{R}_{\mathrm{f}}$ in Figure 3, the investor now has more choices. An ethical investor could choose point $\mathrm{G}$, on the curved line $\mathrm{CD}$. By mixing some of this risky investment with $\mathrm{R}_{\mathrm{f}}$, it's possible to be anywhere on the straight line $R_{f}$ to $G$, extended to point $J$. For an investor unconcerned about ethical issues, the equivalent line is $\mathrm{R}_{\mathrm{f}}$ to $\mathrm{H}$. The logic of portfolio theory tells us that every firm must offer the same level of return for a given risk as line $\mathrm{R}_{\mathrm{f}} \mathrm{H}$ (for investors unconcerned about ethics), or as line $\mathrm{R}_{\mathrm{f}} \mathrm{J}$ (for ethical investors). Hence, we can dispense with the curved lines $A B$ and $C D$ : no investor would choose points like $A$ or $B$ when they could be on line $\mathrm{R}_{\mathrm{f}} \mathrm{H}$ (Barracchini, [17]).

Is there such a thing as a risk-free investment? Since the 2008 global financial crisis, even government-backed securities seem to have a risk due to the possibility of default. In recent years, commentators have discussed the risk of Argentina, Iceland, and Greece becoming bankrupt. Even the USA government's credit rating fell from AAA to AA+ in 2011. This calls into question some assumptions of conventional portfolio theory. This paper does not rely on the existence of a risk-free investment being available, but uses only commercial assets.

If we wish to think of ethical behavior as a third dimension, as Barracchini and Addessi [3] do, we might see points on curve AFB as being approximately vertically below curve CGD; this is the rationale behind the third dimension shown on Figure 4. This may suggest that a portfolio might consist of a point along line CD (more ethical), or a point along $\mathrm{AB}$ (less ethical). In practice, there is no reason to restrict a portfolio in this way: there could be a combination of "more ethical" and "less ethical" assets. As discussed in the literature review, it is unclear if there is a correlation between return and ethical score, or a correlation between risk and ethical score.

A new third dimension has been included in Figure 4: at point $\mathrm{O}$, there is a line pointing approximately toward the reader, representing how "ethical” each potential investment is. Point $\mathrm{O}$ represents the least ethical, i.e. a firm only concerned about profit maximisation. Points above this plane represent more ethical investments, i.e. an investment with a higher $\mathrm{E}$ score. Line $\mathrm{R}_{\mathrm{f}} \mathrm{J}$ can be interpreted as being "higher" in this ethical dimension. A point such as $\mathrm{G}$ in Figure $\mathbf{4}$ is optimal for a saver who prefers ethical investment.

This paper also has the advantage that the "efficient market hypothesis” need not be assumed: by incorporateing expected return into the utility formula, it is possible to encourage the incorporation of stocks with high rates of return in previous data, rather than assume every stock (for a given risk) has the same rate of return.

\section{Data and Methods}

For this paper, we assume that there are organisations which assign each possible investment a "score" regarding how ethical the firm or project seems to be; and assume an investor can choose from a mixture of "ethical" and conventional investments (it is plausible that a commercial investment agency might offer a range of alternative measures of ethical behavior). To assess how "ethical" each possible investment is, we use data from Ethical Consumer Research Association [18]. We do not endorse this website as the definitive assessment of how "ethical" a company is, but use it because it provides a fairly detailed index of ethical behavior (coded from 0: the worst, to 15: the best); and provides evidence on 1513 companies: a fairly large number, compared to other data sources we found. We divide by the mean value, to produce a variable with a mean of 1 .

Financial data used in this paper are from the FAME A database (FAME, [19]): we use annual shareholder returns from 2006 to 2011 (in January 2013, profitability data was not reported in FAME for most companies for 2012 - to prevent possible bias, we exclude all 2012 profitability data). This annual sample is not sufficient to assess correlations between the 177 stocks analysed here; so we use daily "closing price" data (i.e. ignoring dividends, stock splits, etc.) from March 2011 to December 2012. Professional fund managers will have access to up-to-date data sources, which are likely to offer much bigger sample-sizes and more complete data.

To assess the extent to which investors are prepared to sacrifice some of the return on their portfolio return in order to be ethical, this paper assumes a utility function of the form

$$
U=r^{a} E^{c}(\text { risk })^{-b}
$$

where $r$ is the expected return, based on the average for recent years; risk is based on the standard deviation of returns in previous years; and $E$ is the measure of how "ethical" a firm is. We use $a, b$, and $c$ as parametersthey could be chosen by the individual investor. Our assessment of risk is discussed below. 


\section{Practical Implementation}

The previous section outlines the mathematical and conceptual analysis of Barracchini and Addessi [3]. This section explains how factor analysis can be used as the missing link between mathematical abstraction and the practical task facing fund managers.

This paper follows examples of previous empirical research in the field of portfolio theory (e.g. Demsetz and Strahan, [20]; Jeng and Liu, [21]), in applying the statistical technique of principal components analysis (which is based on the mathematical approach of factor analysis); the task is to reduce the risk of a portfolio, by making the portfolio diversified. This paper aims to identify pairs of investments which are as diverse from each other as possible. In this paper, the method is to use daily share price data on as many firms as possible, as explained in the "Data and methods" section. Each firm is treated as a variable, and each day as an observation. Principal components analysis is used to identify different dimensions of variation in these share prices. In our analysis, SPSS produced nine components; we use only the first three of these nine components. Other researchers use a different number of components (e.g. five, in Demsetz and Strahan [20]). Pafka and Kondor [22] claim "classical multivariate analysis generally gives no hints about how many components (factors) are to be included".

When converting from principal components to utility, our research indicates it is common for one share to appear at or near an extreme end of two or more components (for example, if it had a high return). For the principal components approach to reduce portfolio risk, it is vital to choose one share from near each end of the component; our approach is to use the value with the highest utility.

This paper does not attempt to assess what these three components reflect; but in principle, it is likely that researchers could interpret each component by adding more data to the SPSS dataset. Suppose, for the sake of argument, that a component measured the influence of weather on share prices; for this component, we can imagine every share on a line, where one end contains firms which tend to do well if the weather is wet (e.g. umbrella manufacturers), and the other end contains shares in firms which tend to badly in wet weather (e.g. ice-cream sales). Any unexpected information about rainfall could affect these share prices in opposite ways: a period of flooding could raise share prices at one end of this component, and reduce the share price at the other end of the component. Portfolio theory tells us that it would tend to reduce the riskiness of a portfolio if it includes one share from each end of this dimension (represented by the rainfall component). How should a fund manager choose the share with the highest returns? Under the Capital Asset Pricing Model, she does not need to: for a given risk, the expected return will be same, and every asset will be on the "Security Market Line"; the Arbitrage Pricing Model reaches similar conclusions (Ross, Westerfield and Jaffe, [23]). Note, however, that conventional portfolio theory suggests that weights should be used to combine two shares in order to achieve the optimal balance of risk \& return (for a particular saver).

The previous paragraph explains why factor analysis can be helpful to a fund manager who is compiling a portfolio; however, this technique appears unhelpful if her aim is ethical investment. In order to combine ethical investments into a low-risk portfolio, the technique adopted here is the utility function approach in Barracchini and Addessi [3]. We choose a mathematical function to represent how "happy" a client will be about investing in a portfolio of shares, assuming the investor prefers highreturn and low-risk shares in ethical firms. In particular, apply this model:

$$
U=r^{a} E^{c}(\text { risk })^{-b}
$$

For this paper, we use three methods to select a portfolio; each portfolio is based on six shares. The first is to ignore risk (during the selection process), and simply select the six companies with the highest average returns in the period 2004 to 2011. We then adopt two versions of the above formula. One is a simplification: we assume $a=$ zero, which implies the saver is indifferent about how ethical an asset is, and $c=1$. The second application of the above utility formula (for our third portfolio) is to assume $a=0.7$ and $c=0.3$; these are arbitrary values; we chose values of a and c to make $a>c$ (emphasising the ethical aspects of assets more than the return), to make this portfolio noticeably different from our second portfolio. We assess risk by the (absolute value of) the "Principal Components Analysis" component score, reasoning that by combining a share from each end of this spectrum, we are choosing a low-risk combination. In this paper, we assume there are equal values of these two stocks purchased, which is generally the lowest-risk point on the C-shaped curves in Figures $\mathbf{1}$ and $\mathbf{4}$ (future research might experiment with relaxing this assumption, to choose a point slightly higher and to the right of this-it might give a higher utility value).

\section{Results}

The results from the three portfolios are shown in Table 1. Note that these results are purely based on analyzing historic data-it would be unwise to rely on the same risk and return findings in future. Nevertheless, Table 1 gives a guide to how we might expect these three portfolios to perform in future.

The first portfolio was chosen to maximize return, and in this sense it was successful: the return of $90.3 \%$ per year is higher than the other two portfolios $(86.7 \%$ and 
67.7\%). However, the first portfolio was produced without any attempt to minimize the risk, and this explains why the standard deviation of the return (55.7) is higher than the other two portfolios. The second portfolio used principal components analysis to choose three pairs of firms, in which the two firms in a pair complement each other: daily share prices indicate that they tend to be negatively correlated with each other. The third portfolio was also chosen using principal components analysis, but this time the utility function was a combination of three elements, not two: like the second portfolio, it sought to minimize risk and maximize return, but also gave a higher score to firms considered more ethical. The results in Table 1 suggest the technique worked as intended: the average ethical score of these 6 firms is higher (at 1.50) than the first two portfolios. Ethical scores in Table $\mathbf{1}$ are all above 1 (the mean for all 127 firms); this seems surprising, because the first two portfolios were not designed to include ethical firms. The explanation is that more "ethical" firms in this sample have a higher average return than less "ethical" firms (the Pearson correlation coefficient is 0.188 and is statistically significant at the $5 \%$ level); this is a surprising result, but consistent with previous research discussed in the literature review in that ethical firms may take fewer risks.

\section{Conclusions}

In much previous research on ethical investment, firms were divided into "ethical" or "unethical"; in this case, the task of choosing a portfolio is relatively straightforward, in that the usual techniques for choosing a portfolio can be applied by the fund manager-and she benefits from the fact that by excluding unethical assets, there are now fewer assets to choose from. But if we use data from sources such as Ethical Consumer Research Association [18], we have a far more complicated task, because there are different levels of "ethical". For this task, the pioneering work of Barracchini and Addessi [3] seems a promising way forward. However, their analysis is very abstract, and might not be understood by most savers; and applying their techniques seems impossible, because they do not offer a way to choose among a range of assets (for example, the algebraic form of their utility func-

Table 1. Empirical findings from three portfolios.

\begin{tabular}{cccc}
\hline & $\begin{array}{c}\text { Ethical } \\
\text { score }\end{array}$ & Return & $\begin{array}{c}\text { Risk (standard } \\
\text { deviation of return) }\end{array}$ \\
\hline $\begin{array}{c}\text { Portfolio of the six firms with } \\
\text { the highest returns }\end{array}$ & 1.37 & 90.3 & 55.7 \\
$\begin{array}{c}\text { Portfolio minimizing risk \& } \\
\text { optimizing return }\end{array}$ & 1.35 & 86.2 & 50.8 \\
$\begin{array}{c}\text { Portfolio minimizing risk \& } \\
\text { optimizing return and ethical } \\
\text { score }\end{array}$ & 1.50 & 67.7 & 50.9 \\
\hline
\end{tabular}

tion is not given).

The mathematics in Barracchini and Addessi [3] are based on conventional portfolio assumptions; they combine constrained optimization using Lagrange multipliers, together with matrix algebra. They conclude that there is a unique optimal solution to the optimization task they set themselves-in effect, they show that for a given level of return and ethical score, the portfolio's risk can be reduced by combining different stocks. We can see this as an incomplete method: fund managers cannot use it to select stocks for a portfolio.

This paper attempts to bridge the gap between the mathematical model of Barracchini and Addessi [3], and the practical task of choosing assets for a diversified portfolio. The solution adopted here is principal components analysis, a technique widely used in the literature of portfolio theory. For a pragmatic version, this paper relies on the idea of utility maximization, suggested in Barracchini and Addessi [3]; but there seems to be no way to implement the technique without adopting a specific functional form for the utility function. There is no reason to assume the specific functional form adopted in this paper is optimal-it is simply used to illustrate this technique. Future researchers might wish to consider using empirical evidence on investment, to estimate an appropriate mathematical formula based on "revealed preference” (the actual trade-off between ethical values and return: to what extent do savers accept a lower rate of return in order to invest ethically?) An alternative method would be to tailor the emphasis (of risk, return, and ethical score) in the utility function to each individual customer, so a fund manager can provide a more tailored advice.

It appears the empirical evidence reported in Table $\mathbf{1}$ confirms that the interpretation of Barracchini and Addessi [3] adopted for this paper has succeeded: by awarding a higher utility to ethical investments (for a given return and risk), it was possible to use the technique to produce a portfolio with a higher ethical score, and only slightly lower return and risk performance than the other two portfolios.

\section{REFERENCES}

[1] P. Shepherd, "Green and Ethical Investment Comes of Age,” Financial Times, 2011.

[2] M. Hoskin, "Interview with Claudia Quiroz from Cheviot,” Worldwise Investor, 2012. www.worldwiseinvestor.com/news/article/281/Interviewwith-Claudia-Quiroz-from-Cheviot

[3] C. Barracchini and M. E. Addessi, "Ethical Portfolio Theory: A New Course,” Journal of Management and Sustainability, Vol. 2, No. 2, 2012, pp. 35-42. doi:10.5539/jms.v2n2p35

[4] M. Wimmer, "ESG-Persistence in Socially Responsible 
Mutual Funds,” Journal of Management and Sustainability, Vol. 3, No. 1, 2013, pp. 9-15.

[5] R. Havemann and P. Webster, "Does Ethical Investment Pay? EIRIS Research and Other Studies of Ethical Investment and Financial Performance,” EIRIS, 1999. www.eiris.org/files/research\%20publications/doesethicali nvestmentpay99.pdf

[6] M. Arosio, "Issues for Responsible Investors: Impact Investing in Emerging Markets," Responsible Research, 2011.

www.responsibleresearch.com/Impact_Investing_in_Eme rging_Markets-Issues_for_Responsible_Investors.pdf

[7] BMAC, “The Nestlé Boycott," Baby Milk Action Coalition, 2013. http://info.babymilkaction.org/nestlefree

[8] The Mercer Carbon Trust, “A Climate for Change: a Trustee's Guide to Understanding and Addressing Climate Risk,” The Carbon Trust, London, 2005. www.carbontrust.com/media/84964/ctc509-a-climate-forchange-a-trustees-guide.pdf

[9] D. Orrell, "Irrational Economic Man,” World Finance, 2013.

www.worldfinance.com/home/the-econoclast/irrational-e conomic-man

[10] European Commission, "Making a Difference in the World: Europeans and the Future of Development Aid," 2011.

[11] European Commission, "Public Awareness and Acceptance of $\mathrm{CO}_{2}$ Capture and Storage,” 2011.

[12] M. Friedman, "The Social Responsibility of Business is to Increase Its Profits,” The New York Times Magazine, 1970.

[13] C. Sampford and V. Berry, "Shareholder Values, not Shareholder Value: The Role of 'Ethical Funds' and 'Ethical Entrepreneurs' in Connecting Shareholders' Values with Their Investments," Griffith Law Review, Vol. 13, No. 1, 2004, pp. 115-123.

[14] B. J. Richardson, "Environmental Regulation through Financial Organisations: Comparative Perspectives on the
Industrialised Nations,” Kluwer Law International, The Hague, 2002.

[15] A. B. Carroll, "The Pyramid of Corporate Social Responsibility: Toward the Moral Management of Organizational Stakeholders,” Business Horizons, Vol. 34, No. 4, 1991, pp. 39-48. doi:10.1016/0007-6813(91)90005-G

[16] E. Ballestero, M. Bravo, B. Pérez-Gladish, M. Are-nasParra and D. Plà-Santamaria, "Socially Responsible Investment: A Multicriteria Approach to Portfolio Selection Combining Ethical and Financial Objectives,” European Journal of Operational Research, Vol. 216, No. 2, 2012, pp. 487-494. doi:10.1016/j.ejor.2011.07.011

[17] C. Barracchini, “An Ethical Investments Evaluation for Portfolio Selection," Electronic Journal of Business Ethics and Organization Studies, Vol. 12, No. 2, 2007. http://ejbo.jyu.fi/articles/0901_1.html

[18] Ethical Consumer Research Association, "Researcher Verified Ethiscores," 2013. www.corporatecritic.org/companiesatoz/123.aspx

[19] FAME, “UK and Irish Financial Company Information and Business Intelligence,” FAME Database A, 2013. www.bvdinfo.com/Products/Company-Information/Natio nal/FAME.aspx

[20] R. S. Demsetz and P. E. Strahan, "Diversification, Size, and Risk at Bank Holding Companies,” Journal of Money, Credit and Banking, Vol. 29, No. 3, 1997, pp. 300-313. doi:10.2307/2953695

[21] J.-L. Jeng and Q. W. Liu, "Do Idiosyncratic Risks in Multi-Factor Asset Pricing Models Really Contain a Hidden Non-Diversifiable Factor? A Diagnostic Testing Approach,” Journal of Mathematical Finance, Vol. 2, No. 3, 2012, pp. 251-263. doi:10.4236/jmf.2012.23028

[22] S. Pafka and I. Kondor, "Estimated Correlation Matrices and Portfolio Optimization,” Physica A, Vol. 343, 2004, pp. 623-634. doi:10.1016/j.physa.2004.05.079

[23] S. A. Ross, R. W. Westerfield and J. F. Jaffe, "Corporate Finance,” Irwin, 1988. 